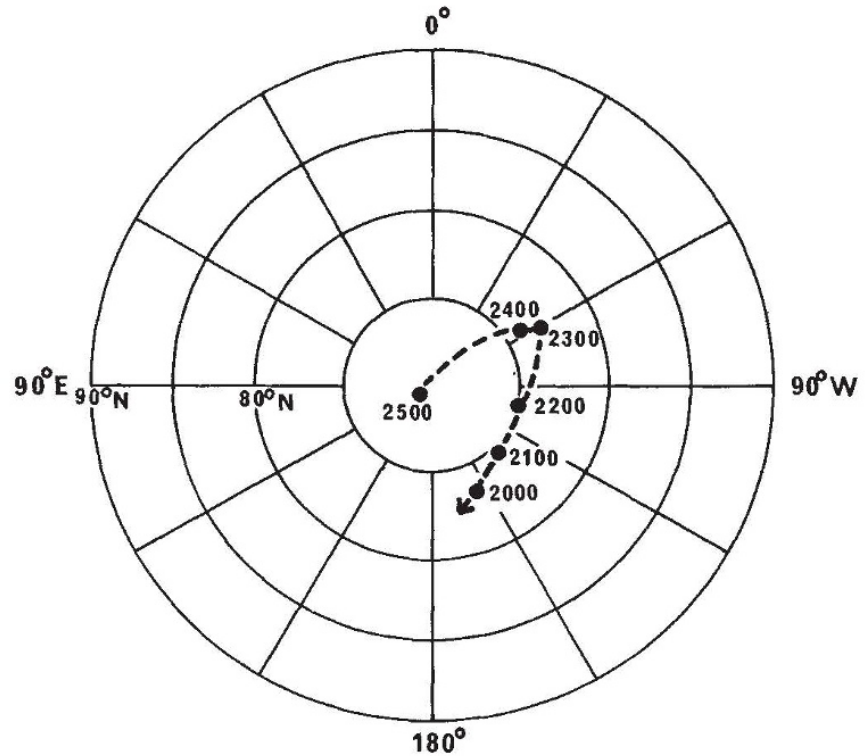

Fig. 4 Path of virtual pole positions.

zontal line the age uncertainty of each baked earth. The path of virtual pole positions derived from our calculation is shown by the smooth curve in Fig. 4 . The period required for complete rotation of the clockwise loop in the path is approximately 500 years. Similar clockwise loops have been observed in Japanese $^{6,7}$ and North American ${ }^{8}$ archaeomagnetic data ${ }^{6,7}$. In both cases, however, more recent baked earths less than 2,000 years old were dealt with. Nevertheless the period of the looping motion was also 500 years. This difference of the Iranian secular field from the field in other parts of the world may represent only the behaviour of the Earth's magnetic field.

The magnetic charts now being prepared from these data may be used as an archaeometric standard with which to date other remains from this part of the world.

N. KaWAI

K. HiROOKA

T. NAKAJIMA

Faculty of Engineering Science,

Osaka University,

Osaka, Japan

Faculty of Literature and Science,

K. TOKXEDA

Shimane University,

Matsue, Japan

Istituto Italiano per il Medio ed Estremo Oriente,

Roma, Italy

Received October 29; revised December 6, 1971.

${ }^{1}$ Irving, E., Paleomagnetism (Wiley, New York, 1964).

2 Nagata, T., Rock Magnetism (Maruzen, Tokyo, 1961).

3 Collinson, D. W., Creer, K. M., and Runcorn, S. K., Methods in Palaeomagnetism (Elsevier, Amsterdam, 1967).

4 Tosi, M., East and West (New Ser.), 19, 283 (1969).

5 Fisher, R. A., Proc. Roy. Soc. Lond., A217, 295 (1953).

6 Kawai, N., and Hirooka, K., J. Geomag. Geoelec., 19, 217 (1967).

7 Kawai, N., Hirooka, K., and Tokieda, K., Earth Planet. Sci., 3, 48 (1967).

8 Watanabe, N., and DuBois, R. L., J. Geomag. Geoelec., 17, 395 (1965).

\section{Rate of Solution of Gaseous Sulphur Dioxide at Atmospheric Concentrations}

LIss $^{1}$ has calculated the rate of exchange between sulphur dioxide and environmental water. We report here experimental work which verifies the results of his calculations. The rate of solution of $\mathrm{SO}_{2}$ at $20^{\circ} \mathrm{C}$ was examined by passing a nonlaminar flow of air (bulk velocity $\sim 1.5 \mathrm{~cm} \mathrm{~s}^{-1}$ ) and ${ }^{35} \mathrm{SO}_{2}$ at concentrations around $300 \mu \mathrm{g} \mathrm{m}^{-3}$ over stirred sodium perchlorate solutions. The $p \mathrm{H}$ values of these solutions were adjusted by addition of sodium hydroxide or perchloric acid because ionic strength exerts little effect on rate of uptake. Oxidation of the sulphur (IV) anions in sodium perchlorate solution is small over the time scale involved (unpublished data of P. B.).

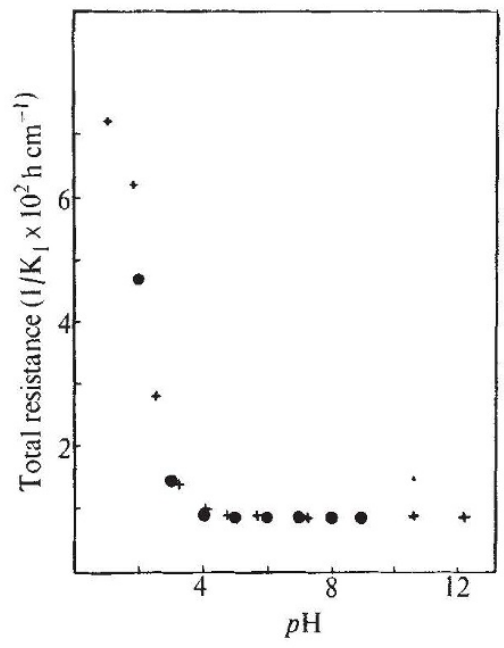

Fig. 1 A comparison of experimental and calculated values of total resistance. Liss $^{1}$; + , experimental,

The total concentration of sulphur species in solution was determined by liquid scintillation counting of the aqueous solution. The uptake rate and $p \mathrm{H}$ remained constant during each experiment $(1,000 \mathrm{~s})$. Values calculated from these experimental measurements were expressed as resistance on a liquid concentration basis $\left(1 / K_{1}\right)$. This total resistance was also determined from Liss's data using Danckwerts's equation ${ }^{2}$, where $1 / k_{1}$ and $1 / k_{\mathrm{g}}$ are the liquid and gas phase resistances and $H$ is the Henry's law constant.

$$
1 / K_{1}=1 / k_{1}+1 / H k_{g}
$$

The excellent agreement between experimental and calculated values is shown in Fig. 1.

P. BRIMBLECOMBE

D. J. Spedding

Chemistry Department,

University of Auckland,

Private Bag,

Auckland

Received October 22; revised December 6, 1971.

1 Liss, P. S., Nature, 233, 327 (1971).

2 Danckwerts, P. V., Gas-Liquid Reactions, 145 (McGraw-Hill, London, 1970).

\section{BIOLOGICAL SCIENCES}

\section{Human Brain Monoamine Oxidase: Multiple Forms and Selective Inhibitors}

IT is well recognized that monoamine oxidase (monoamine: $\mathrm{O}_{2}$ oxidoreductase (deaminating), EC 1.4.3.4) (MAO) plays an important role in the degradation of biologically active monoamines in the brain ${ }^{1,2}$. There is much evidence pointing to changes in monoamine metabolism in mental illnesses 